\title{
The role of networked publics in immigration debates
}

\section{Ojala, Markus}

Edward Elgar

2021-12-07

Ojala, M 2021, The role of networked publics in immigration debates . in M McAuliffe (ed.), Research Handbook on International Migration and Digital Technology . Elgar Handbooks in Migration , Edward Elgar , Cheltenham , pp. 330-343 . https://doi.org/10.4337/9781839100611.00035

http://hdl.handle.net/10138/338268

https://doi.org/10.4337/9781839100611.00035

cc_by_nc_nd

acceptedVersion

Downloaded from Helda, University of Helsinki institutional repository.

This is an electronic reprint of the original article.

This reprint may differ from the original in pagination and typographic detail.

Please cite the original version. 
This is the final version of a chapter published in the Research Handbook on International Migration and Digital Technology. The published chapter can be accessed at: https://doi.org/10.4337/9781839100611.00035

Cite: Ojala, Markus (2021). "The role of networked publics in immigration debates." In Research Handbook on International Migration and Digital Technology (edited by Marie McAuliffe), pp. 330-343. Cheltenham: Edward Elgar.

\title{
The role of networked publics in immigration debates
}

\author{
Markus Ojala \\ University of Helsinki \\ (markus.ojala@helsinki.fi)
}

\begin{abstract}
Networked publics are groups that communicate with each other over common concerns using digital media tools and online platforms. As a sign of their growing political significance in liberal democracies, networked publics have become increasingly visible actors in immigration debates. At the same time, these publics operate in a conflictual relationship not only with political authorities but also with one another. Particularly with the rise of nationalist-populist parties and activism, the public debate on immigration has become increasingly divided and polarised between anti-immigrant conservatives and pro-immigrant liberal publics. The resulting contradictions between the democratic promises and worrying realities of online participation highlight the importance of examining the complex nature of networked publics and their role in shaping societal responses to immigration.
\end{abstract}

Keywords: immigration, public debate, publics, networked publics, online platforms, public sphere 


\section{INTRODUCTION}

The academic interest towards the impact of network technologies on the public debate has grown substantially over the past decade as digital networks and social media platforms have become increasingly central for how news and information is produced, consumed and shared. As with other phenomena involving technology, there are both optimistic expectations and sceptical warnings concerning the effects of online media. On one hand, the digitalisation of communication enhances the opportunities for public participation in democratic processes. Through online platforms, people have new means to come together and influence the generation of public agendas both locally and nationally, and even across national boundaries.

On the other, recent controversies across the world have demonstrated that digital networks can be used as efficient tools for spreading disinformation and mobilizing hate, for example, against minorities.

This chapter focuses on the formation of 'networked publics' around the issue of immigration and the ways in which digital technologies are being used to shape public debates over immigration. Networked publics consist of groups discussing common concerns using digital media and online platforms. Scholarship has not only explored the nature of online communication but also sought to understand the ways in which networked publics can intervene in political processes and the generation of the public agenda. It appears that in recent years, networked publics have become increasingly visible and influential players also in immigration policy. The tension between the democratic promises and worrying realities of online communication highlights the importance of examining the complex nature of networked publics and their role in shaping societal responses to the major trends of the twentyfirst century, including immigration.

The first two sections of this chapter introduce the public and 'networked' public as theoretical concepts and research topics. Having established these conceptual grounds, the chapter turns to immigration as a public issue. The third section discusses why immigration has turned into a highly charged topic in many liberal democracies over the past two decades. The fourth section examines the roles of networked publics in contemporary immigration debates. It should be noted at the outset that the focus will be on the national public debates of countries of net immigration that reside mostly in the global north. The broader migration debates, whether in the countries that experience extensive emigration or at international forums, remain beyond the scope of this chapter. 


\section{PUBLICS, ISSUES AND CONFLICTS}

As a term, the public has always been difficult to pin down and it continues to carry multiple meanings (Price 1992; Warner 2002). In contemporary research on political communication, we can roughly distinguish between two approaches. One of them, typically related to media and cultural studies traditions, derives its perception of the public from the notion of (media) audience (Varnelis 2008; boyd 2011): the public consists of those who read, watch and listen to media contents and are thus addressees of communication. The term public is used here to emphasise that rather than being passive receivers, audiences actively interpret and remake the messages and further distribute them in their own communities and networks. In today's digital media environment, people shape the circulation of political communication, alternating between the roles of the receiver and the disseminator of opinions and information (Castells 2009).

The second approach builds on the liberal tradition of democratic theory and associates the public with civic practices (e.g., Habermas 1996; Dahlgren 2005). This tradition views the public as a loosely defined and unorganised aggregation of citizens who engage in argumentation over common affairs, critically scrutinizing the conduct of state authorities, denouncing abuses of power and establishing collective views on the pressing matters of the day. It holds that citizens form a public when they participate in various kinds of civic activities and discuss current affairs in public spaces. The term public is thus used in a manner that somewhat diverges from the former perspective, which equates the public with audiences or the people as such. Against this all-encompassing notion, the liberal-democratic tradition stresses that people as users and consumers of media are not members of any public by default. They only become such members through active participation in the public debate.

At the heart of the liberal-democratic notion of the public is an idea of democracy as a set of cultural practices through which people participate in the public debate and the political system becomes responsive to people's concerns. In other words, this perspective emphasises that the operation of democracy entails not only that the public expresses its consent to government legislation, ultimately granting legitimacy to the political system as a whole, but that the public also participates in political processes, actively informing decision-making institutions about its preferences. In its civic activities, the public embodies, reproduces and strengthens a democratic culture (O’Mahony 2013). Accordingly, when analysing various forms of political 
communication, this perspective focuses on the democratic qualities of public participation and its impacts on political decision-making. This is also why the notion of the citizen is central when talking about publics. It is mainly on the merit of being citizens with the corresponding rights and duties that people can participate in democratic processes. This obviously does not deny the possibility that non-citizens and even non-human agents such as online bots can, at times, have a notable impact on public debates.

Contemporary public spheres are commonly understood to be fragmented and differentiated, comprising a multitude of 'publics' that are overlapping and without fixed social and temporal boundaries (Habermas 1996; Friedland et al. 2006). Thematic publics form around specific issues that their participants perceive important enough to merit discussion. They are matters which cannot be dealt with privately and call for collective responses. Indeed, issues and publics cannot be separated; we would hardly recognise any shared problems in society unless there was a public, an aggregation of people engaged in discussing and promoting a given issue as a matter of collective discretion. Publics aim to bring the issue to the attention of decisionmakers, forcing them to respond. Insofar as they are successful, the decision-makers themselves are drawn into the public.

Many critical scholars of the public sphere emphasise that, in addition to being divided, contemporary public spheres are highly conflictual. Different publics and 'counterpublics'-referring to publics formed by subordinated groups, representing marginalised views and positioning themselves in confrontation with dominant groups-regularly clash with each other in ideological and political contestation over the definition of public problems (Fraser 1992; Warner 2002; Fenton 2016). Publics also define themselves in relation to their political and ideological opponents. Instead of speaking about 'issues', the critical perspective thus emphasises the importance of conflicts in mobilizing people and provoking them to public action.

As a result, the communication of publics has both internal and external dimensions. Internally, it constructs the sense of 'us versus them', that is, collective identity and a sense of shared interests. Externally, the public aims to communicate to those who do not (yet) belong to it, including decision-making authorities, adversarial groups and the general audience. In contemporary heavily mediated societies, the public agenda of which is shaped in the interplay between major news media organizations and social media platforms, a public can bring an 
issue into the awareness of large numbers of people only when it is influential enough to penetrate through the gatekeeping of professional media organizations or can successfully harness the social media's operational logic.

\section{NETWORKED PUBLICS AND POLITICAL CONTESTATION}

The great curiosity-and concern-of late over the impact of digital information and communication technologies on various aspects of social life have also been reflected in studies of the public sphere, paving the way for analyses of how digital networks shape the dynamics of public debate (e.g., Castells 2009; Chadwick 2013; Fenton 2016; Iosifidis and Wheeler 2016). While the notion of the 'networked public' is not always explicitly present in this literature, one of the main issues addressed is how digital networks alter the public operation of actors and the formation of publicly acting collectives. This is exactly what the term 'networked public' aims to capture when exploring the impact of information and communication technologies on democratic politics and the public sphere. However, when talking about the networked public in this context, we should keep in mind that the notion carries certain liberal-democratic undertones as discussed in the previous section. That means it should be understood as having a different meaning than related terms such as online users, 'networked individuals' (Castells 2009) or online communication in general.

The notion of networked publics implies not only that publics increasingly take shape and act in and through digital networks but also that these communication technologies affect the nature and operation of publics in various ways (Varnelis 2008; boyd 2011). The generation of publics and their activities-exchanging views, organizing and participating in public events, bringing in new members, reaching out to other people, and so on-is greatly enhanced by the availability of digital tools, which make it is easy to record, archive, replicate and spread messages. Network technologies facilitate communication that is less bounded by geography and more inclusive of diverse views, more dialogical and less hierarchical in nature (Papacharissi 2004). However, while the digital platforms and associated technologies provide certain structural affordances and limitations, they (alone) do not determine the democratic quality of societal discussion, which ultimately depends on intentional action, values, interests and political purposes. 
The participation in networked publics tends to be highly individualistic; they are formed by 'connected individuals' (Maireder and Schwarzenegger 2012) for whom it is easy to engage and disengage from the conversation. Being unorganised and largely spontaneous formations, networked publics lack clear leaders and authorities. The research of online participation often highlights the nature of networked publics as spaces for affective expression, the construction of identities and the formulation of common lines of action (e.g., boyd 2011; Papacharissi 2015).

While most of online activities are oriented to diversion, entertainment and social networking, they always contain the possibility of becoming political (Dahlgren 2005; Fenton 2016; Roslyng and Blaagaard 2018). Any interaction among groups can develop into a formulation of public problems that require societal and political responses. When becoming political, networked publics often draw in various types of actors, including civil society representatives, politicians, journalists, celebrities and experts (Wang and Chu 2019). The news media has an important role in the creation of networked publics who use professional journalism about current affairs as a fuel for discussion (Maireder and Schlögl 2014).

Despite the new capacities for transnational communication brought about by digital technologies, networked publics continue to be bounded by political systems as well as by language. Publics strive for political and cultural influence-that is, to shape the ways people live together-and that tends to lead them to orient towards the nation-state and its institutions. Accordingly, national public spheres form the principal field of operation for networked publics, and participation in the public debate typically requires the use of the official or dominant language. This is not to deny that many of today's central political issues, including climate change, immigration and digital surveillance, generate international discourses and forms of publicity. Similarly, some of the major recent protest movements and popular uprisings, including the Arab Spring, the Occupy movement and anti-austerity protests in Europe, were notable for their use of digital networks to mobilise publics across borders (Castells 2015; Papacharissi 2015; Iosifidis and Wheeler 2016). But even in those cases, most of the public mobilisation focused on effecting political change at the national level-with the partial exception of the anti-austerity movement that also targeted European Union institutions.

In online domains, people typically seek spaces where they can exchange ideas with people who share their attitudes, views and interests. As a result, networked publics often comprise 
primarily like-minded people. They tend to engage in advocacy rather than critical and selfreflective discussion, and their modes of operation resemble those of social movements or activists (Dahlgren 2005; Bennett and Segerberg 2013). Minorities, too, establish their own counterpublics with the help of digital networks (Renninger 2015; Kuo 2018). In this way, the Internet further drives the fragmentation of the public sphere, leading to the diversification of political identities. Different views do not necessarily meet, at least not in a mutually respectful manner, divides between groups deepen and the public debate becomes increasingly conflictual (Sunstein 2017; Dutton 2018).

\section{THE POLITICAL INFLUENCE OF NETWORKED PUBLICS}

Networked publics are often understood to mark citizens' increased salience and influence in the public sphere. Yet it is less than clear what this salience means in terms of the political debate more generally and how it influences political processes. One of the perceived impacts is the capacity of networked publics to shape the public agenda by bringing in underrepresented viewpoints. The news media, which have been traditionally oriented to institutional and elite sources, nowadays regularly tap into online conversations for new stories and reactions, enabling publics to bring their concerns into the broader public view (Chadwick 2013; Maireder and Schlögl 2014). In this reading, networked publics constitute an influential new actor in a media environment characterised by the interplay of online publics and professional news organizations.

A somewhat bolder argument is to see networked publics having a direct impact on political decision-making and government. According to this view, the new communication technologies enable people to increasingly monitor the conduct of powerful institutions and individual decision-makers, expose their wrongdoings, mobilise criticism against them and demand direct responses from them (Dutton 2009; Keane 2009). When managing to disrupt the public agenda, typically through scandals and other controversies, these activities can have significant outcomes, prompting authorities not only to publicly justify their decisions but to reassess their conduct whether in fear of losing public legitimacy or because feeling morally compelled to do so (Bovens 2007; Moore 2014).

Generally speaking, networked publics seem to have strengthened the importance of publicity in the everyday politics and government. When making decisions and communicating them, 
policymakers and officials must increasingly take into account the potential reactions of networked publics and plan ahead the public representation of policies (Louw 2010). However, the rise of networked publics does not signal a decisive shift of political power from established elites to citizens. In online spaces, attention is a scarce resource and political influence continues to be exerted by the few, not the many (Hindman 2008). Because of their large follower bases, elite opinion leaders are in a privileged position to get people involved in an issue, mobilise publics and direct their attention to new developments (boyd 2011).

Politicians, corporations and organised civil society actors have quickly learned to see new media technologies as tools that they can use to exert their power and influence in the public arena (Castells 2009; Chadwick 2013). They aim to harness the power of networked publics to achieve their strategic purposes. Moreover, most of today's popular online spaces for political communication are controlled by transnational corporations and engineered for profit creation (Allmer 2013). Established interests and profit-seeking motives thus continue to have a major impact on the public agenda even in online environments, shaping the formation and evolution of networked publics as well as their broader political impact.

We must also bear in mind that the public agenda is highly volatile and tends to be focused only on a few issues at a time. Therefore, the rising importance of publicity in policymaking should not be interpreted as a general tendency. Even as the role of the public debate in daily politics grows in some policy areas, most of the policymaking and administration continues to be carried out outside the glare of publicity. In recent decades, issues related to immigration have frequently become subject to public controversies, potentially contributing to the impact of networked publics on immigration policy.

\section{IMMIGRATION AS A PUBLIC ISSUE}

As discussed previously, the contemporary public spheres of liberal democracies tend to be divided into contesting and mutually hostile publics. Immigration is one of the most central issues that both mobilises publics and brings them into a conflictual relationship with one another. While the social media is often accused of creating such a hostile public environment around immigration, it results from much more fundamental transformations in western societies and the global political economy (Žižek 2017). The number of people forced to migrate either due to violent conflicts or the destruction of livelihoods has risen dramatically 
at a time when societies in the global north have suffered from economic crises, unemployment, precarisation, rising inequality and disinvestment in public services.

These developments can only be understood against the backdrop of newly emergent political and ideological cleavages in liberal democracies (Crouch 2011; Mouffe 2013). In the 1990s, the traditional confrontation between the social-liberal left and the market-liberal right was undermined by economic globalisation and the demise of socialism. The neoliberal consensus over market-led globalisation narrowed the political divergence of established parties, emptying the public debate over economic policy of any real alternatives and diminishing the capacity of the dominant political forces to mobilise publics. Concurrently, political conflicts began to move to the terrain of culture, lifestyle and social group relations. That gave a new lease of life to socially conservative groups whose approach to economic and social policies were often ambiguous but who articulated their political project in terms of defending the nation and national sovereignty, protecting traditional professions and ways of life-and restricting immigration (Eatwell and Goodwin 2018). In recent years, the national-conservative populist parties have been able to attract a sizable support base and make themselves visible in public debates in many if not most of the western countries. In doing so, they have presented immigration and the related issues of national values and lifestyles as the definitive questions for citizens to mobilise around publicly and politically.

This brief sketch may help explain why immigration has become a national question that recurrently shapes the agenda of parliaments and mainstream news media in many western countries. As such, immigration is a complex and multifaceted topic that includes a wide variety of issues (Gans et al. 2012; Swain 2018). Politicians, advocacy groups and citizens argue not only over such political and administrative considerations as naturalisation processes and immigrants' rights, but also over the costs of immigration to taxpayers, the impact of unskilled immigrants on the labour markets and other economic issues. Moreover, various social and cultural issues, including the social and cultural integration of immigrants to host societies, as well as multiculturalism and racism are often hotly debated themes related to immigration.

As the range of these issues of contestation suggests, publics tend to be highly divided on immigration-related matters. Indeed, even though immigration is often negatively portrayed and covered in mainstream news media (Allen and Blinder 2013; Georgiou and Zaborowski 
2016), studies on public opinion indicate that people's perceptions are rather complex and divided on immigration (Freeman et al. 2013; Gilligan 2015). Perceptions alter depending on which group of immigrants the person is thinking about, and on the particular detail of immigration policy. Moreover, rather than questioning immigration itself, people may often have negative views of immigration policy or the way immigration is handled by the government. The political contestation over the framing of individual issues between those favouring liberal immigration policies and those striving for new restrictions on immigration is often key in swaying the public opinion (Sen and Mamdouh 2008).

Immigration is a transnational phenomenon by definition and as such an issue one might expect to be primarily discussed in various kinds of 'transnational public spheres' (Fraser 2007). Yet even within supranational polities such as the European Union, it has proven to be practically impossible to mobilise cross-border debates over immigration outside the very limited public spaces involving governments, international bureaucrats, experts and civil society organizations. Most people and media continue to orientate themselves around national political institutions and centres of decision-making power. Often the language of communication also confines the immigration debate to the national level.

Language barriers also partly explain why immigrants themselves tend to be relegated to a marginal position within national public spheres. Immigrants are typically the objects of public claims made by others but seldom claims-makers themselves. Moreover, being a diverse and fragmented group, immigrants are not well placed to establish a public of their own around the issue of immigration. This is not to say that immigrants fail to participate in practices and forums of public communication. Ethnic minorities and diasporas, for instance, certainly look for ways to engage, and they may occasionally be highly involved in the immigration debates of their receiving countries. On the whole, however, immigration is mostly debated and contested in national public spheres by other people than immigrants.

\section{IMMIGRATION AND NETWORKED PUBLICS}

One of the main concerns in recent scholarship on immigration has been the rise of antiimmigrant parties and movements and the simultaneous prevalence of anti-immigrant voices and sentiments in public discourse. Many studies have focused on the online mobilisation of anti-immigrant users and its impact on the public debate and political processes. For instance, 
an analysis of US immigration debates on Twitter found that anti-immigrant groups took advantage of the social networking platform for mobilisation and were able to steer the overall debate in their favour (Flores 2017). More generally, digital networks have been found to make it easier for anti-immigrant activists and individuals to spread hostile messages against particular immigrant or minority groups (Ekman 2015; Kaján 2017; Merrill and Åkerlund 2018).

Such dissemination of anti-immigrant perspectives on social media may not alter users' views on immigration but can change their behaviour, inciting new people to join these public activities. Concurrently, incivility and hate speech often dominate online debates on immigration (Musolff 2015; Pöyhtäri et al. 2019; Santana 2015). Conversations tend to be highly confrontational with users aggressively denouncing politicians and other public figures with whom they disagree. Online commentary is typically provoked by news media reports, and users often direct their criticism at the newsmakers themselves in addition to those expressing pro-immigrant views and positions (Bartlett and Norrie 2015; Kaján 2017).

Roger Eatwell and Matthew Goodwin (2018) have argued that anti-immigrant parties have tapped into a widespread discontent among citizens with the elitist nature of liberal-democratic politics and the increasing economic inequality, as well into their concerns about the scale and pace of ethnic change. Demands for more restrictive immigration policies are often tied to a broader ideology of 'national populism' that does not simply address immigration as an economic burden and a threat to cultural values and ways of life but also denounces liberal institutions for their failure to represent the voices and interests of the less-educated and more conservative segments of the population. This overlapping of negative attitudes on immigration with anti-elitism can also be witnessed in online discussions about immigration, where antiimmigrant views are often linked to grievances about unemployment and the erosion of the welfare state (Gibson et al. 2018). Political and media attention to the plight of refugees is juxtaposed with the absence of similar alarm about crumbling social services and domestic inequalities (Ojala, Kaasik-Krogerus and Pantti 2019). Such claims provoke a sense of being a second-class citizen and paves the way for denouncing elites as those who have abandoned their own people.

The focus of much of the recent research on the spreading of anti-immigrant views online ought not to lead us to disregard the existence of strong liberal and pro-immigrant publics that also 
make efficient use of networked spaces (e.g. Siapera 2004; Burke and Goodman 2012; Grover et al. 2019; Macgilchrist and Böhming 2012). Their discourses of solidarity, human rights and resistance to xenophobia and racism can have as significant an impact on the public debate as the publics demanding more restrictive immigration policies. This may be the case particularly during periods such as the so-called 'refugee crisis' in Europe in 2015, when the rapidly increasing number of migrant deaths in the Mediterranean and the surge of asylum seekers created a sense of great urgency among European policymakers and civil society. Digital networks were used by refugee organizations, activists and volunteers not only to organise aid to asylum seekers. With the help of opinion leaders, including left-wing politicians, human rights organizations and journalists, they also mobilised the public in demonstrations of solidarity and in defence of asylum seekers' rights, as well as to gain visibility for proimmigrant views in the public debate to counter anti-immigrant discourses and disinformation (Holmes and Castañeda 2016; Siapera et al. 2018; Ojala, Pantti and Laaksonen 2019).

To be sure, we can speak of 'the' public debate on immigration only on a highly abstract level as online debates on immigration are not conducted similarly across digital networks. Studies of online debates during the so-called refugee crisis in Europe indicate that popular discussion forums and users' comment sections of online newspapers were often dominated by antiimmigrant views, whereas the blogosphere and platforms like Twitter and Facebook-highly fragmented spaces in themselves - tended to include a more even ratio of liberal-humanitarian and anti-immigrant discourses (Siapera et al. 2018; Ojala, Kaasik-Krogerus and Pantti 2019; Pöyhtäri et al. 2019). This suggests that the contribution of the Internet to the multiplication of spaces of debate and to the fragmentation of the public sphere (Dahlgren 2005; Fenton 2016) can also be evidenced in the immigration debate.

In recent years, a lot of concern has been raised over the impact of disinformation, fake news and foreign information operations on national political debates (Bennett and Livingston 2018; Spohr 2017). While the spreading of lies, distortions and propaganda is by no means a new phenomenon in political communication, the networked media environment and targeted political messaging, enabled by the pervasive collection of user data, provide organised actors with new means to manipulate the public opinion. In addition, citizen actors themselves actively post online hearsay, rumours and speculation, which can rapidly spread with the help of various alternative and counter media sites, blogs and video blogs. The immigration debate is obviously vulnerable to these phenomena, and the dissemination of rumours and 
disinformation tends to become particularly extensive during emergencies or exceptional circumstances. For instance, Pöyhtäri and colleagues (2019) found that Finnish online users often spread negative rumours and false information about local asylum seekers during the 2015 'migration crisis'. A few anti-immigrant online discussion forums, blogs, videoblogs and counter-media sites were effective in creating nation-wide attention to these often fabricated local 'news'. These events illustrate how individual users and minor media initiatives, through both intentional and unintentional spread of false information, may shape the public debate on immigration, often entirely in the absence of any organised or external information operation. Whether originating from foreign and organised sources or domestic and individual activities, fake news and disinformation obviously distort people's knowledge environment (Dahlgren 2018). As such, they may play a part in debilitating the public sphere as an arena of societal debate, for instance, by accelerating political polarisation.

There are indeed some indications that online platforms exacerbate the polarisation of the immigration debate into two opposing camps. As the consumption of news and discussion on current affairs increasingly takes place in social networking sites, the very networks that users form by being followed or following others may consist of relatively like-minded people who mostly confirm the existing opinions and beliefs they hold about immigration. Aside from users' voluntary networking choices, the recommendation algorithms of the platforms may enhance this effect, trapping people within 'echo chambers' or 'filter bubbles' that expose them to only one-sided views (Pariser 2012; Spohr 2017); although some studies suggest that the problem has been exaggerated and that most users in fact avoid echo chambers in online networking and news consumption (e.g., Dubois and Blank 2018; Bruns 2019). Nevertheless, even if most people continue to be exposed to contradictory information and views, the public debate on immigration appears to be driven by highly partisan actors who rarely seek the middle ground or reach out to those they oppose. As a result, even though online debates in the multitude of forums and platforms may feature a greater number of themes than what circulates in the mainstream news media (Nerghes and Lee 2019; Pöyhtäri et al. 2019), the diversity of viewpoints does not necessarily increase (Siapera et al. 2018).

Neither do the online platforms seem to significantly reallocate power and influence in the immigration debate. Even though the number of participants engaged in public argumentation over immigration has been greatly expanded by the digital means of communication, public attention continues to be highly unequally distributed. Instead of being levelling devices, social 
media platforms tend to concentrate agenda setting power and opinion leadership to very few actors who more often than not represent established elites from the domains of politics, media and the organised civil society (Ojala, Pantti and Laaksonen 2019; Siapera et al. 2018). On occasions, a non-elite individual may certainly make an impact on the immigration debate, for instance, by leaking information from within the immigration system or exposing malpractices of asylum officials; yet they usually need mainstream media professionals or public figures as message sponsors to gain broader attention for their cause.

What, then, can we say about the political outcomes that may result from the engagement of networked publics in immigration debates? Thus far, there have been very few studies that have addressed the relation between online debates and immigration policies. Nevertheless, one indication of the significance of publics in the politics of immigration can be found in the European Union, whose member states differ markedly in terms of the relative openness or restrictedness of their immigration policies. Marc Howard and Sara Goodman (2018) have argued that these differences cannot be explained based on the countries' diverging demography, economic indicators or other structural factors. The relevant factor explaining the differences appears instead to be the success of anti-immigrant groups in making immigration a salient issue in national public debates. In practically all EU countries, more restrictive immigration policies have been historically associated with the mobilisation of an antiimmigrant sentiment in the public arena by far-right groups or parties. Conversely, those member states that carried out significant liberalisation of immigration policies in the 1980s and 1990s were connected by the absence of a visible anti-immigrant party or movement. At least in liberal democracies, immigration policy seems to be partly responsive to shifts in the public debate.

Another indication of the political impact of networked publics can be discerned at the level of politicians' and officials' communicative practices. Ojala, Pantti and Laaksonen (2019) studied the public interactions between Finnish immigration officials and citizens during the so-called refugee crisis in 2015 and 2016. They discovered that the volume of online challenges and critiques directed at the government's immigration agency exploded following the surge of asylum seekers and were expressed in various online forums. In the early phase of the 'crisis', most of the criticism came from conservative anti-immigrant publics that protested against the opening of new refugee reception centres and suspected the immigration officials of being too lenient in their asylum decisions. However, after the acceptance rate of asylum applications 
dropped significantly in the spring of 2016, the agency faced mounting critiques from liberal pro-immigrant publics, as well as highly critical press coverage, which continued till the end of that year.

Moreover, Ojala and colleagues (ibid.) found that throughout the period, the immigration agency repeatedly addressed its critics both on its Twitter account and through the national news media, attempting to explain and justify its actions and policies. While these efforts were hardly successful in quelling public discontent, this interaction created an unprecedented level of responsiveness between immigration officials and its publics while making the operation of the immigration system as a whole more transparent to large segments of the population. Moreover, the heightened attention on and criticism of the immigration agency also provoked both internal and external reviews of Finnish asylum processes. The authors concluded that in this case networked publics operated as 'agents of accountability' for the immigration system, capable of forcing authorities to provide explanations and justifications of their use of public power. The publics thus contributed to what John Keane (2009) has dubbed 'monitory democracy', enforcing the social accountability of public authorities.

\section{CONCLUSION}

Much of the existing research on online debates over immigration focuses on the practices and discursive strategies of participants in advancing either fear and anger towards immigrants or feelings of empathy and solidarity. One of the main challenges is to look beyond such practices of shaping the debate and addressing the political impact of networked publics. As Chris Gilligan (2015) points out, it is not at all evident that governments always respond to the pressure of the public opinion in immigration matters; instead, it often appears that political leaders themselves are influential shapers of the public opinion. Moreover, the publics hold diverse attitudes and opinions regarding immigration, and there are various actors, institutions and contextual factors that mediate the impact of public opinion on the administration, including political parties, advocacy groups, media organizations, legal frameworks and immigration patterns. There is thus much to be discovered in terms of 'the conditions under which the public influence policy-makers, and vice versa, as well as identifying the mechanisms through which this influence is exerted' (ibid., p. 1385).

Being in full agreement with that research agenda, I conclude by reiterating some useful starting points for future studies on the basis of the research reviewed in this chapter. First, 
owing to the long-term economic and political transformations, national populism is turning into a persistent phenomenon in the public life of liberal democracies. With their growing impact on public life, national populists are increasingly capable of defining the issues around which societal, political and cultural contestations are fought. Therefore, even as future migration trends are difficult to predict, immigration is unlikely to wither away as a source of political conflict any time soon in the global north. Both national-conservative and liberal publics have become increasingly confrontational in recent years in their attitudes and activities regarding the political system and immigration administration. The publics aim to shape the public debate and manipulate the public opinion, and they engage in the scrutiny and critique of officials and policymakers.

Second, digital networks and social media platforms certainly play a role in the rise of contesting publics around immigration in the sense that both anti-immigrant parties and movements and liberal groups have taken advantage of the new media technologies and tools to spread their message and rally people around their cause. The kind of public activities that were traditionally the domain of activist groups and social movements are now available to technology-savvy individuals. Without any organisational resources, they can mine online databases for information and make it known to others, publish sensitive information, launch online addresses and target political leaders with critiques. When they successfully interact with the professional news media, networked publics can set into motion public controversies, derail the political process and force authorities to respond. Moreover, far-right activists, in particular, have adopted practices and techniques such as disinformation, fake news, trolling, online shaming and doxing to disrupt the public debate and harass those they consider as political opponents. They can make the life of politicians, officials and researchers increasingly difficult by instigating other users to attack them online and harass them offline.

Finally, while the capacity of networked publics to shape immigration debates, monitor the conduct of immigration authorities and even influence certain policies seems to be growing due to the increased salience of immigration in the public agenda, we should be cautious about jumping to any assumptions about their contribution to advancing the democratisation of policymaking or a more inclusive public debate on immigration. Even with the emergence of new forms of online communication and social media networking, established actors constantly find ways to exert their influence by manipulating the publics that form on these platforms. 
The elites largely maintain their grip on the public agenda to preserve existing power hierarchies.

Moreover, it is evident that some of the activities of the networked publics have deteriorated the public sphere and undermined the conditions for a democratic debate. The problem lies not only in anti-immigrant publics who spread hateful and racist discourses and aim to silence humanitarian voices; liberal pro-immigrant publics also often engage in derogatory and exclusionary rhetoric about their opponents (Burke and Goodman 2012; Gibson et al. 2018). The resulting polarisation of the immigration debate into highly antagonistic camps may be partly driven by the logics of digital networks. However, while the private online media platforms have certainly benefited from and contributed to the increasingly polarised political environment, the roots of these problems lie in the practices of the networked publics themselves and are not determined by the technologies used for their intra-public and interpublic communication. 


\section{References}

Allen, W., and S. Blinder (2013), 'Migration in the news: Portrayals of immigrants, migrants, asylum seekers and refugees in national British newspapers, 2010-2012', Migration Observatory report, Oxford: University of Oxford.

Allmer, T. (2015), Critical Theory and Social Media, London; New York: Routledge.

Bartlett, J. and R. Norrie (2015), Immigration on Twitter: Understanding Public Attitudes Online, London: Demos.

Bennett, W. L. and A. Segerberg (2013), The Logic of Connective Action: Digital Media and the Personalization of Contentious Politics, Cambridge: Cambridge University Press.

Bennett, W. L. and S. Livingston (2018), 'The disinformation order: Disruptive communication and the decline of democratic institutions', European Journal of Communication, 33 (2), 122-39.

Bovens, M. (2007), 'Public accountability', in E. Ferlie, L. E. Lynn, and C. Pollitt (eds), The Oxford Handbook of Public Management, New York: Oxford University Press, pp. 182208.

boyd, d. (2011), 'Social network sites as networked publics', in Z. Papacharissi (ed), A Networked Self: Identity, Community, and Culture on Social Network Sites, New York: Routledge, pp. 39-58.

Bruns, A. (2019), Are Filter Bubbles Real?, Cambridge: Polity Press.

Burke, S. and S. Goodman (2012), “"Bring back Hitler's gas chambers”: Asylum seeking, Nazis and Facebook - a discursive analysis', Discourse \& Society, 23 (1), 19-33.

Castells, M. (2009), Communication Power, Oxford: Oxford University Press.

Castells, M. (2015), Networks of Outrage and Hope: Social Movements in the Internet Age, 2nd ed., Cambridge: Polity.

Chadwick, A. (2013), The Hybrid Media System, Oxford: Oxford University Press.

Crouch, C. (2011), The Strange Non-Death of Neoliberalism, Cambridge: Polity Press.

Dahlgren, P. (2005), 'The internet, public spheres, and political communication: dispersion and deliberation', Political Communication, 22 (2), 147-62.

Dahlgren, P. (2018), 'Media, Knowledge and Trust: The Deepening Epistemic Crisis of Democracy', Javnost, 25 (1-2), 20-7.

Dubois, E. and G. Blank (2018), 'The echo chamber is overstated: the moderating effect of political interest and diverse media', Information, Communication \& Society, 21 (5), $729-45$. 
Dutton, W. H. (2009), 'The Fifth Estate emerging through the network of networks', Prometheus, 27 (1), 1-15.

Dutton, W. H. (2018), 'Networked publics: multi-disciplinary perspectives on big policy issues', Internet Policy Review, 7 (2), accessed at https://doi.org/10.14763/2018.2.795.

Eatwell, R. (2018), National Populism: The Revolt against Liberal Democracy, London: Penguin.

Ekman, M. (2015), 'Online Islamophobia and the politics of fear: manufacturing the green scare', Ethnic and Racial Studies, 38 (11), 1986-2002.

Fenton, N. (2016), Digital, Political, Radical, Cambridge: Polity Press.

Flores, R. D. (2017), 'Do anti-immigrant laws shape public sentiment? A study of Arizona's SB 1070 using Twitter data', American Journal of Sociology, 123 (2), 333-84.

Fraser, Nancy (2007), 'Transnationalizing the public sphere: on the legitimacy and efficacy of public opinion in a post-Westphalian world', Theory, Culture \& Society, 24 (4), 7-30.

Freeman, G. P., R. Hansen and D. L. Leal (eds.) (2013), Immigration and Public Opinion in Liberal Democracies. London: Routledge.

Friedland, L. A., T. B. Hove and H. Rojas (2006), 'The networked public sphere', Javnost, 13 (4), 5-26.

Gans, J., E. M. Replogle and D. J. Tichenor (eds.) (2012), Debates on U.S. Immigration, Thousand Oaks: Sage.

Georgiou, M. and R. Zaborowski (2016), 'Media coverage of the "refugee crisis": a crossEuropean perspective'. Council of Europe Report No. DG1(2017)03, Brussels: Council of Europe.

Gibson, S., M. Crossland and J. Hamilton (2018), 'Social citizenship and immigration: employment, welfare, and effortfulness in online discourse concerning migration to the United Kingdom'.

Gilligan, C. (2015), 'The public and the politics of immigration controls', Journal of Ethnic and Migration Studies, 41 (9), 1373-90.

Grover, T., E. Bayraktaroglu, G. Mark and E. H. R. Rho (2019), 'Moral and affective differences in U.S. immigration policy debate on Twitter', Computer Supported Cooperative Work, 28 (3), 317-55.

Habermas, J. (1996), Between Facts and Norms, Cambridge: MIT Press.

Hindman, M. (2009), The Myth of Digital Democracy, Princeton: Princeton University Press. 
Holmes, S. and H. Castañeda (2016), 'Representing the "European refugee crisis" in Germany and beyond: deservingness and difference, life and death', American Ethnologist, 43 (1), 12-24.

Howard, M. M. and S. W. Goodman (2018), 'The politics of citizenship and belonging in Europe', in C. M. Swain (ed), Debating Immigration, Cambridge: Cambridge University Press, pp. 329-46.

Iosifidis, P. and M. Wheeler (2016), Public Spheres and Mediated Social Networks in the Western Context and Beyond, London: Palgrave Macmillan.

Kaján, E. (2017), 'Hate online: anti-immigration rhetoric in Darknet', Nordia Geographical Publications, 46 (3), 3-22.

Keane, J. (2009), 'Monitory democracy and media-saturated societies', Griffith Review, 24, $47-69$.

Kuo, R. (2018), 'Visible solidarities: \#Asians4BlackLives and affective racial counterpublics', Studies of Transition States and Societies, 10 (2), 40-54.

Louw, E. (2010), The Media and Political Process, Los Angeles: Sage.

Macgilchrist, F. and I. Böhmig (2012), 'Blogs, genes and immigration: online media and minimal politics', Media, Culture \& Society, 34 (1), 83-100.

Maireder, A. and S. Schlögl (2014), '24 hours of an \#outcry: the networked publics of a socio-political debate', European Journal of Communication, 29 (6), 687-702.

Maireder, A. and C. Schwarzenegger (2012), 'A movement of connected individuals: social media in the Austrian student protests 2009', Information Communication and Society, 15 (2), 171-95.

Merrill, S. and M. Åkerlund (2018), 'Standing up for Sweden? The racist discourses, architectures and affordances of an anti-immigration Facebook group', Journal of Computer-Mediated Communication, 23 (6), 332-53.

Moore, M. H. (2014), 'Accountability, legitimacy, and the court of public opinion', in M. Bovens, R. E. Goodin, and T. Schillemans (eds), The Oxford Handbook of Public Accountability, Oxford: Oxford University Press, pp. 632-646.

Mouffe, C. (2013), Agonistics: Thinking the World Politically, London: Verso.

Musolff, A. (2015), 'Dehumanizing metaphors in UK immigrant debates in press and online media', Journal of Language Aggression and Conflict, 3 (1), 41-56.

Nerghes, A. and J.-S. Lee (2019), 'Narratives of the refugee crisis: a comparative study of mainstream-media and Twitter', Media and Communication, 7 (2), 275-89.

O'Mahony, P. (2013), The Contemporary Theory of the Public Sphere, Oxford: Peter Lang. 
Ojala, M., S. Kaasik-Krogerus and M. Pantti (2019), 'Presidential speeches and the online politics of belonging: affective-discursive positions toward refugees in Finland and Estonia', European Journal of Cultural Studies, 22 (2), 164-79.

Ojala, M., M. Pantti and S.-M. Laaksonen (2019), 'Networked publics as agents of accountability: online interactions between citizens, the media and immigration officials during the European refugee crisis', New Media \& Society, 21 (2), 279-97.

Papacharissi, Z. (2004), 'Democracy online: civility, politeness, and the democratic potential of online political discussion groups', New Media \& Society, 6 (2), 259-83.

Papacharissi, Z. (2015), Affective Publics, Oxford: Oxford University Press.

Pariser, E. (2012), The Filter Bubble, New York: Penguin Press.

Price, V. (1992), Public Opinion, Newbury Park: Sage.

Pöyhtäri, R., M. Nelimarkka, K. Nikunen, M. Ojala, M. Pantti and J. Pääkkönen (2019), 'Refugee debate and networked framing in the hybrid media environment', International Communication Gazette, accessed at https://doi.org/10.1177/1748048519883520.

Renninger, B. J. (2015), “Where I can be myself ... where I can speak my mind": networked counterpublics in a polymedia environment', New Media \& Society, 17 (9), 1513-29.

Roslyng, M. M. and B. B. Blaagaard (2018), 'Networking the political: on the dynamic interrelations that create publics in the digital age', International Journal of Cultural Studies, 21 (2), 124-38.

Santana, A. D. (2015), 'Incivility dominates online comments on immigration', Newspaper Research Journal, 36 (1), 92-107.

Sen, R. and F. Mamdouh (2008), The Accidental American: Immigration and Citizenship in the Age of Globalization, San Francisco: Berret-Koehler.

Siapera, E. (2004), 'Asylum politics, the Internet, and the public sphere: the case of UK refugee support groups online', Javnost - The Public, 11 (1), 79-100.

Siapera, E., M. Boudourides, S. Lenis and J. Suiter (2018), 'Refugees and network publics on Twitter: networked framing, affect, and capture', Social Media + Society, 4 (1), 1-18.

Spohr, D. (2017), 'Fake news and ideological polarization', Business Information Review, 34 (3), 150-60.

Sunstein, C. R. (2017), \#Republic: Divided Democracy in the Age of Social Media, Princeton: Princeton University Press.

Swain, C. M. (ed.) (2018), Debating Immigration, Cambridge: Cambridge University Press. 
Wang, R. and K.-H. Chu (2019), 'Networked publics and the organizing of collective action on Twitter', Convergence: The International Journal of Research into New Media Technologies, 25 (4), 393-408.

Varnelis, K. (ed.) (2008), Networked Publics, Cambridge: MIT Press.

Warner, M. (2002), 'Publics and counterpublics', Public Culture, 14 (1), 49-90.

Žižek, S. (2017), Against the Double Blackmail: Refugees, Terror and Other Troubles with the Neighbours, London: Penguin. 